\title{
Drug pricing and reimbursement decision making systems in Mongolia
}

\author{
Gereltuya Dorj ${ }^{*}$, Bruce Sunderland ${ }^{2}$, Tsetsegmaa Sanjjav $^{3}$, Gantuya Dorj $^{4}$ and Byambatsogt Gendenragchaa ${ }^{5}$
}

\begin{abstract}
Background: It is essential to allocate available resources equitably in order to ensure accessibility and affordability of essential medicines, especially in less fortunate nations with limited health funding. Currently, transparent and evidence based research is required to evaluate decision making regarding drug registration, drug pricing and reimbursement processes in Mongolia.

Objective: To assess the drug reimbursement system and discuss challenges faced by policy-makers and stakeholders.

Methods: The study has examined Mongolian administrative documents and directives for stakeholders and analysed published statistics. Experts and decision-makers were interviewed about the drug pricing and reimbursement processes in Mongolia.

Results: Decisions regarding Mongolian drug registration were based on commonly used criteria of quality, safety, efficacy plus some economic considerations. A total of 11.32 billion Mongolian National Tugrugs (MNT) [5.6 million United States Dollars (USD)] or $12.1 \%$ of total health expenditure was spent on patient reimbursement of essential drugs. The highest reimbursed drugs with respect to cost in 2014 were the cardiovascular drug group. Health insurance is compulsory for all citizens; in addition all insured patients have access to reimbursed drugs. However, the decision making process, in particular the level of reimbursement was limited by various barriers, including lack of evidence based data regarding efficacy and comparative cost-effectiveness analysis of drugs and decisions regarding reimbursement.

Conclusions: Drug registration, pricing and reimbursement process in Mongolia show an increasing trend of drug registration and reimbursement rates, along with lack of transparency. Limited available data indicate that more evidence-based research studies are required in Mongolia to evaluate and improve the effectiveness of drug pricing and reimbursement policies.
\end{abstract}

Keywords: Drug pricing policy, Reimbursement, Cost, Pharmaceuticals, Mongolia

\section{Introduction}

Mongolia is an East-Asian country bordered with Russia and China. It is the 19th largest country in the world with an estimated area of $1,566,460 \mathrm{~km}^{2}$. After the collapse of the Soviet Union, Mongolia has undergone radical change in financial support for health, education and social security. Despite steady economic growth with promising developments occurring in the last 15 years, recent statistics show that infectious diseases are no longer the leading cause of morbidity, instead

\footnotetext{
* Correspondence: gereltuya.dorj@mnums.edu.mn

${ }^{1}$ Department of Clinical Pharmacy and Pharmacy Administration, School of

Pharmacy and Biomedicine, Mongolian National University of Medical

Sciences, Ulan Bator, Mongolia

Full list of author information is available at the end of the article
}

lifestyle, behaviour - dependent diseases, including circulatory system diseases, cancer and injuries have become the leading causes of mortality and morbidity [1].

During the years of socioeconomic transition in Mongolia, total health expenditure (THE) as a share of Gross Domestic Product (GDP) has increased from 3.3\% (1995) to $5.4 \%$ by $2010[2,3]$.

Despite existing government regulations, inappropriate use of medicines [4] and high drug costs are evident in Mongolia [5]. Although illegal, people can purchase prescription medicines, including antibiotics without prescription from some private pharmacies [6, 7]. Previous reports have indicated lower out of pocket (OOP) expenses with about $10 \%$ of outpatients and $16 \%$ of 
inpatients paying OOP fees for hospital visits in 2011 [8]. However, the study did not specify whether these fees were for medicines or treatment.

\section{Overview of the Mongolian health sector}

The Mongolian health sector is regulated by the Ministry of Health $(\mathrm{MOH})$, the Ministry of Finance (MOF), the Ministry of Human Development and Social Welfare (MOHDSW), the Ministry of Education and Science (MOES), the regulating agency -General Agency for Specialised Inspection (GASI) and former government implementing agencies such as the Department of Health (DOH), the Department of Physical Culture and Sport (DOPS), and the city/aimag (provincial) health departments.

The MOH and MOHDSW are the third-party payers involved in purchasing and resource allocation in health care. The government health budget is managed by the $\mathrm{MOH}$, and the Health Insurance Fund is managed by Social Insurance General Office (SIGO- under the MOHDSW). The fund for social health insurance (HI) is a single national insurance fund that uses its local branches to collect revenue and pay for insured care and it has been a stable source of health financing in Mongolia since 1990s. In addition to having government agency status, the SIGO is also overseen by the Social Insurance National Council (SINC) appointed by the State Great Khural.

Despite having a low share of THE, it is the only health financing mechanism that exercises some elements of contracting and purchasing. The government is the dominant player in making $\mathrm{HI}$ decisions therefore it is used as a substitute for the government budget.

\section{Pharmaceutical sector in Mongolia}

The Division for Pharmaceutical and Medical Devices of the $\mathrm{MOH}$ is responsible for oversight of the main functions of the pharmaceutical sector policy, regulation and coordination. The Division for Health Inspection of the General Agency for Specialized Inspection ensures compliance with major laws and legislation as it relates to quality assurance and distribution inspection. A Human Drug Council consisting of experts in the field and representatives of all relevant ministries leads the pharmaceutical sector, particularly in the development of standards, guidelines and procedures, including drug registration. The Drug Regulatory Unit is responsible for technical work for the Human Drug Council including the registration of medicines and medical devises, licensing of specialists and providers, issuance of import and export licenses, monitoring and reporting adverse drug reactions, monitoring medicines marketing and advertisement, promoting rational use of medicines and developing a national pharmacopeia and standards.
In addition, a Special Permission Committee of the $\mathrm{MOH}$ monitors the functional activities of drug producers and grants approval for manufacturing, importing and selling drugs in Mongolia (Figs. 1 and 2).

The drug reimbursement decision is approved by the Health Insurance Fund (HIF), which is incorporated within the General Department of Social Insurance and it is regulated by the Ministry of Human Development Social Welfare of Mongolia.

The Drugs Act of Mongolia was promulgated in 1998 and aimed to ensure good quality, effective and safe drugs were available to the Mongolian population. Following the Drug Act, the National Drug Policy of Mongolia (NMPM) was adopted in 2000, revised and approved by the State Great Khural in 2014. Ministerial legislation corresponding to reimbursement includes the Health Insurance Law, approved by the State Great Khural 2015 and the Resolution on the List of Essential Medicines to be reimbursed by the HIF, approved by the National Committee on Social Insurance of Mongolia in 2016.

The Policy regulates the procurement, manufacturing, financing, quality assurance, distribution, and appropriate use of drugs. In order to ensure the availability of the most essential medicines at all levels, the government has adopted an Essential Drugs List, developed on the basis of recommendations by the World Health Organization (WHO). This List has been available since 1991 and it has been revised several times with the seventh being completed in 2014 [9].

The procurement of health products including medicines for only public health facilities (hospital pharmacies) is regulated by the Law on Public Procurement and Guidelines approved by the $\mathrm{MOH}$. Tertiary-level health facilities and aimag health departments have their own tendering committees. Ulaanbaatar city carries out a tender for all its district hospitals in the urban area. Medicines procured and sold at private retail pharmacies are supplied by wholesaling companies, however the government has no regulation on price.

The Mongolian pharmaceutical sector is predominantly dependent on its manufacturing and private business organizations due to $100 \%$ privatization of all pharmaceutical wholesalers. Mongolia was defined as a low-income country with THE of 556 billion MNT or $2.6 \%$ of GDP in 2013 [10], hence evidence based decision making and optimum use of available resources is of high importance.

\section{Drug distribution system in Mongolia}

Most of the imported drugs sold in Mongolia come from the Russian Federation, China, India and other eastern European countries. Drug supply companies and pharmacies must be licensed in order to undertake drug 


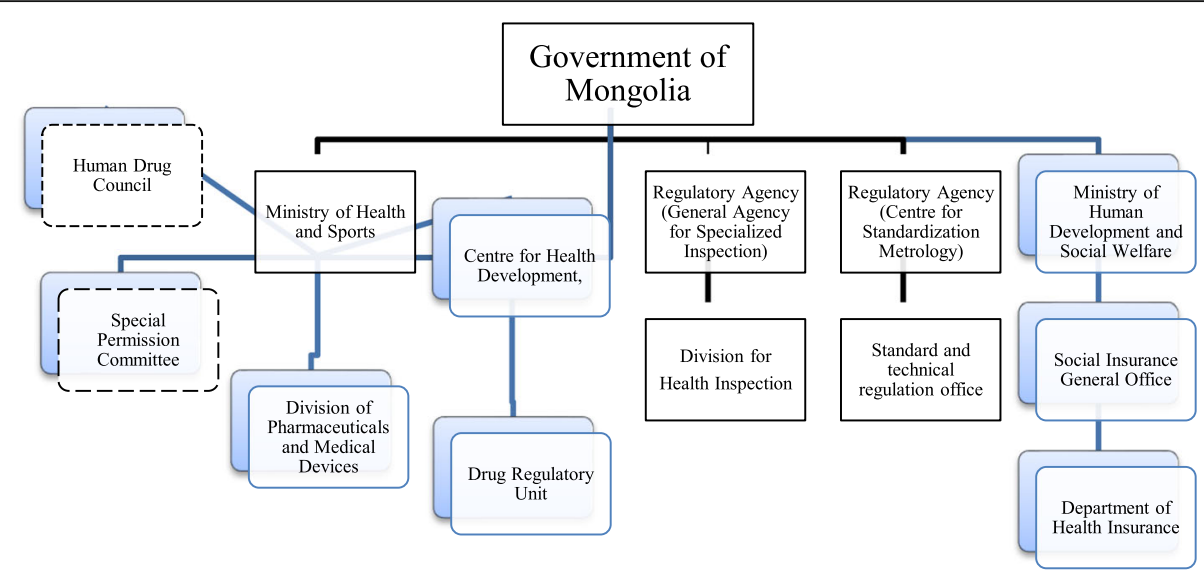

Fig. 1 Organizational structure of the Mongolian pharmaceutical policy and regulation. Note: Human Drug Council and Special Permission Committees are expert professionals

supply functions. With the accelerating growth of the private sector, the drug supply business has proven to be very successful. Currently, 1190 pharmacies are operating all over Mongolia and $75 \%$ of the private pharmacies have one or two branches. There were 306 pharmacies working under the drug revolving fund (DRF) initiative [1]. According to the latest report, 24 drug factories were officially permitted to operate as drug manufacturers and their share was approximately $12 \%$ (66 Billion MNT) of the total local pharmaceutical market [11]. There were 591 new drugs (salts or dosage forms), 48 raw materials registered and the registration period was extended for a total of 428 drugs in 2014 [11].

The latest survey on medicines prices and affordability in Mongolia was completed using WHO methodology in 2010 and it reported that the affordability of the lowest priced generics and most sold generics in the public sector was good for most conditions, with standard treatment costing 1 days' wage or less. Treatments costing more than 1 days' wage of the lowest paid unskilled government worker included a pack of
30 amlodipine tablets to treat hypertension (1.6 days) [5]. In the private sector, the majority of treatments cost less than the daily wage of the lowest paid government worker when the lowest price generics were used. Hypertension treated with enalapril $(10 \mathrm{mg} \mathrm{cap} / \mathrm{tab})$ for 30 days costs 2.5 days' wages, simvastatin $(20 \mathrm{mg}$ cap/ tab) 30 days 2.7 days' wages are clearly unaffordable even when generics are used.

The price of medicines has not been regulated by the Government since 1997 and a 10\% value-added-tax (VAT) was introduced in 1999. Taxes, duties and other government charges applied to medicines include 5\% customs duty for imported medicines. In the private sector, add-on costs represent $90.1 \%$ of the final patient price for imported originator brands, $115.5 \%$ for imported generics, and $74.4 \%$ for locally produced generics. Registration fees do not differ between originator brands and generic equivalents. However, registration fees are lower for locally produced than for imported medicines; hence the government encourages local production.

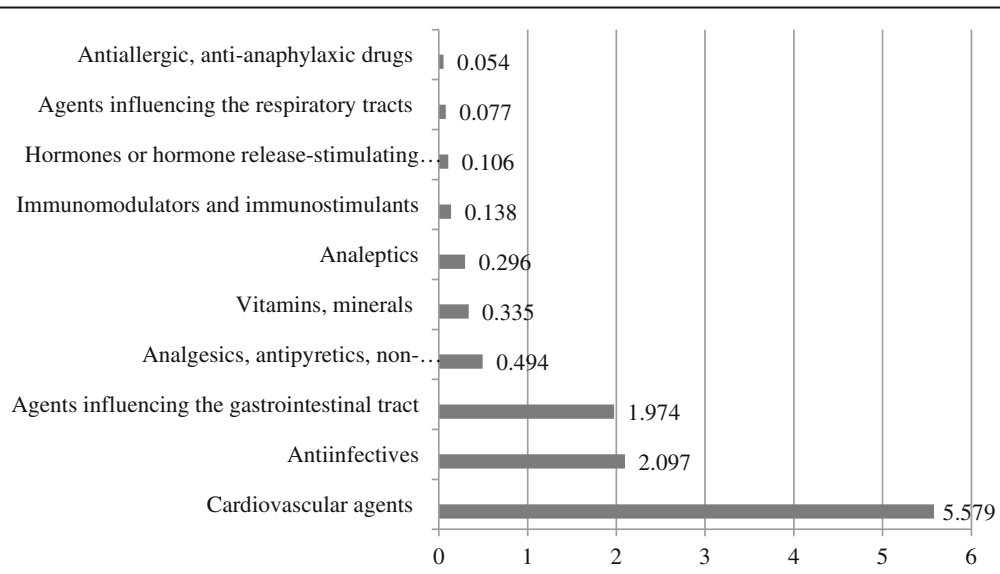

Fig. 2 Proportion of reimbursed drugs, by pharmacological classification (Billion MNT), 2014 (adapted from Health Indicators of Mongolia, 2014) 
There are no public pharmacies, except those located in public hospitals whose service is limited to inpatients. Furthermore, the government controls dispensing fees for reimbursed essential medicines and some data are available to support the insurers view on the dispensing fee.

The drug reimbursement system and health insurance scheme have been developed since 1994. The latest revision of the list for reimbursed essential drugs was approved by the SHI in 2016 [12]. The main purpose was to expand the range of health insurance benefits and ensure greater access to essential drugs in primary health-care services by the insured population which is compulsory for all population groups [12].

To date, insured ambulatory patients have access to a total of 134 essential drugs partly reimbursed by the Health Insurance (HI) providing that these drugs were prescribed by a family doctor (in urban settings), village (soum) hospital doctor or district (bagh) feldsher (in rural settings) and dispensed by a $\mathrm{HI}$ designated or contracted pharmacy.

A list containing the cost of certain essential drugs is also available once it has been approved by the HI. This list gives the maximum price level for certain drugs provided to insured ambulatory and stipulates how much of this cost should be covered under HI. A decision to include the drug in the reimbursement list is based on mortality and morbidity rates for the last 2 years and drug consumption listed by pharmacological classification. No further information of specific analysis for reimbursement decision making was available.

Drug reimbursement funding is an important expenditure to ensure the budget is used optimally. However, there is a lack of detailed information in regards to drug pricing and reimbursement decisions in Mongolia. Considering the importance of clear and transparent processes for drug pricing and government funded reimbursement, this study has aimed to examine the pharmaceutical drug pricing and reimbursement decision making in Mongolia.

\section{Methods}

\section{Documents relevant to drug reimbursement}

Existing documents regarding drug reimbursement, selection and procurement of essential medicines, appropriate use of medicines including regulations enacted by the Mongolian Government, legislative documents and published internal regulations of the Human Drug Council, Ministry of Health of Mongolia (MOH), Pharmaceuticals and Medical Devices Division, $(\mathrm{MOH})$, Social Health Insurance Office (SHIO), and the Division of Finance and Insurance, the Ministry of Finance, Mongolia (MOF), including approved State Policy on
Medicines and Medical Devices (2014), Health Law (2010), regulation to reimburse essential medicines by the Health Insurance, approved by the Health Insurance Subcommittee, National Social Insurance Committee, \#03, 2011, anupdated list of reimbursable essential medicines, Health Insurance Subcommittee, National Social Insurance Committee (2013.07.31), General requirement for pharmacies in Mongolia, MNS 260:2011,\#13 Regulation for registration of medicines, raw materials, biologically active compounds in Mongolia, approved by the Health Minister, 2015 were reviewed by all authors in this study. More documents in relation to the statistics and published data related to drug pricing and drug reimbursement, published and unpublished annual reports reimbursement of medicines, including Mongolian statistical annual report, National Statistical Office, Annual report of Health Insurance Office, Survey of medicine prices, availability, affordability and price components in Mongolia, 2012 [5] were collected and reviewed.

In addition, websites of several organisations and agencies including drug regulatory authorities were examined for relevant information and reports. The search was complemented by hand searches of bibliographies and, in the case of doubt, by telephone and email communication with the institutions themselves.

\section{Interviews}

In order to collect more detailed information on the decision making process and evaluation methods, key stakeholders including the authorities and officers in charge of drug registration, procurement and reimbursement including the Head of Pharmaceuticals and Medical Devices Division, Health Insurance Office, Head of Allocation and Monitoring of Health Budget, Ministry of Finance, Human Drug Council Member, Officer in charge for drug procurement services, policy implementation, $\mathrm{MOH}$ were interviewed. The interview consisted of questions regarding information about the respondent [13] and reimbursement, including the (i) assessment, (ii) appraisal and (iii) decision making processes. Assessment included the quantification of the clinical, pharmacotherapeutic efficacy and pharmacoeconomic value of a drug. Appraisal sought to gauge society's willingness to pay for a drug by weighing assessment outcomes against other (societal) criteria which reflect health system objectives. Decision making was defined as a value judgement from a broader societal perspective, considering the health system policy objectives as well as non-health care related objectives.

The interview guide (in Mongolian) was piloted with four potential respondents to ensure the validity; technical functioning, relevance and understanding of the questions. No major omissions were identified. These responses were not used further in the study. 
As Mongolian versions of the documents are available, the study engaged two professional translators to complete translations from Mongolian to English and vice-versa to assure accuracy and minimize any possible bias. These translators were unknown to each other [14]. The author made adjustments resulting from any inconsistencies. (Data are available upon request from the corresponding author).

\section{Data analysis}

Standard descriptive statistics were used to summarize demographic data and responses to the interviews. Questions regarding the frequency of assessment, appraisal and decision making were answered. All documents were analysed in a qualitative matter and according to an analytic informational framework that had been developed in advance. Results were summarised narratively and presented in a related manner. Comparisons between groups were performed using the Chi-square test, logistic regression or KruskalWallis test with a pairwise comparison as appropriate. A $p$ value of $<0.05$ was taken as being significantly different.

\section{Results}

\section{Drug registration process in Mongolia}

All drugs used in the country are registered once agreement and authorization by the Human Drug Council has been given. The General Agency for Specialized Inspection (GASI) is in charge of ensuring that only registered drugs enter the market for public use. Locally manufactured drugs are registered for 2 years, whereas imported drugs are given a 4-year (regular registration) or 5-year (fast-track registration) period. The drugs should be of a good quality, compliant with good manufacturing practice (GMP) regulations to qualify for registration. The applicant must prepare documents including data regarding efficacy, safety and adverse events, comparative efficacy with similar drugs, approval history, contraindications, warnings, precautions, monitoring parameters, pharmacokinetics, patient compliance and information of cost, insurance and freight (CIF) cost for registration.

All medicines should be registered in the State Medicines Register which is divided into two categories as medicines available with and without prescription (overthe-counter, OTC).

\section{Drug reimbursement process in Mongolia}

Detailed analysis of HI statistics indicates that 11.32 Billion MNT (5.59 Million USD) was spent on reimbursement of essential drugs, and that half of the reimbursement was spent on cardiovascular agents (5.579 Billion MNT) in 2014 (Table 1). Considering the health indicators, the prevalence of cardiovascular diseases is listed as priority causes of mortality and morbidity [1].

A detailed analysis of reimbursed cardiovascular drugs indicated that the highest was for amlodipin $(3,059,489,957 \mathrm{MNT})$ and the lowest was for enalapril $(69,266 \mathrm{MNT})$. In terms of analgesics, antipyretics, non-steroidal anti-inflammatory drugs, the most reimbursed item was ibuprofen syrup 9,205,575,118 MNT) and the least dispensed item with reimbursement was paracetamol tablets (12 pack, 140,486 MNT) (Table 1).

The proportion of pharmaceutical expenditure has been relatively stable ranging from 12 to $14 \%$ of total health expenditure in the last 5 years, whereas the reimbursement provided by the $\mathrm{HI}$ has steadily increased over the last 6 years. The revised list of reimbursable essential medicines contained a total of 134 medications prescribed by a legal prescriber/physician the reimbursement level has ranged from 40 to $83.3 \%$ of the cost of the medicine. This list indicates the maximum retail price that a retail pharmacy can charge. This indicates that the government is fixing the total cost of these medicines charged by retail pharmacies.

The latest statistics indicate that the population coverage has increased to $99 \%$ which means essentially the whole population is covered for essential drugs [1].

Until 2014, there were no price control mechanisms specific to generic drugs, however the latest revision of the NDPM indicates that the maximum price of essential medicines shall be regulated by the Government [15]. Therefore the only price control is on reimbursed essential medicines in Mongolia.

\section{Discussion}

This study has indicated that the Mongolian drug registration process is based on commonly used decision making criteria that are applied in many countries $[13,16]$. These criteria include safety, efficacy and some economic aspects. Official reports and documents also have shown that Mongolian HI operates with some advantages, including a $92.2 \%$ of insurance coverage in Mongolia [2]. However, due to low payment in regards with salary (lowest: 192000 MNT or 101.3 USD) and pension (lowest: 145.200 MNT or 87 USD), the health care benefits of an estimated 1.33 million MNT or 798 USD per person annually are reported to be rather weak [17].

As acknowledged in many other countries, the drug reimbursement process is a very challenging task shared by various authorities with different interests [18]. The Ministry of Health of Mongolia works towards delivering quality health care and increased efficacy and accessibility of drugs to all patients, whereas the Ministry of Finance and Ministry of Human Development and Social Welfare aim to increase the health insurance coverage 
Table 1 Drug categories and reimbursement data for essential drugs for the year 2014

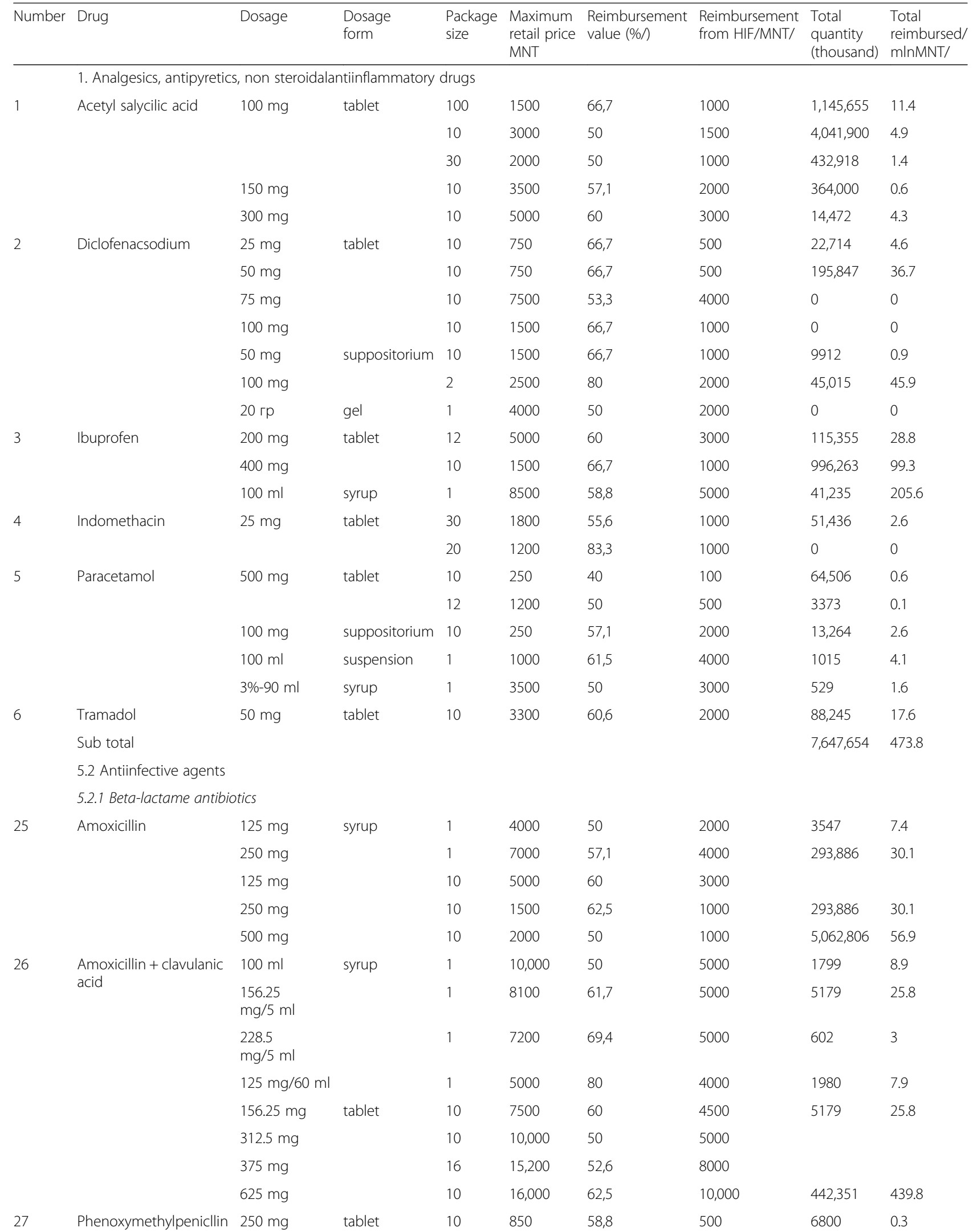


Table 1 Drug categories and reimbursement data for essential drugs for the year 2014 (Continued)

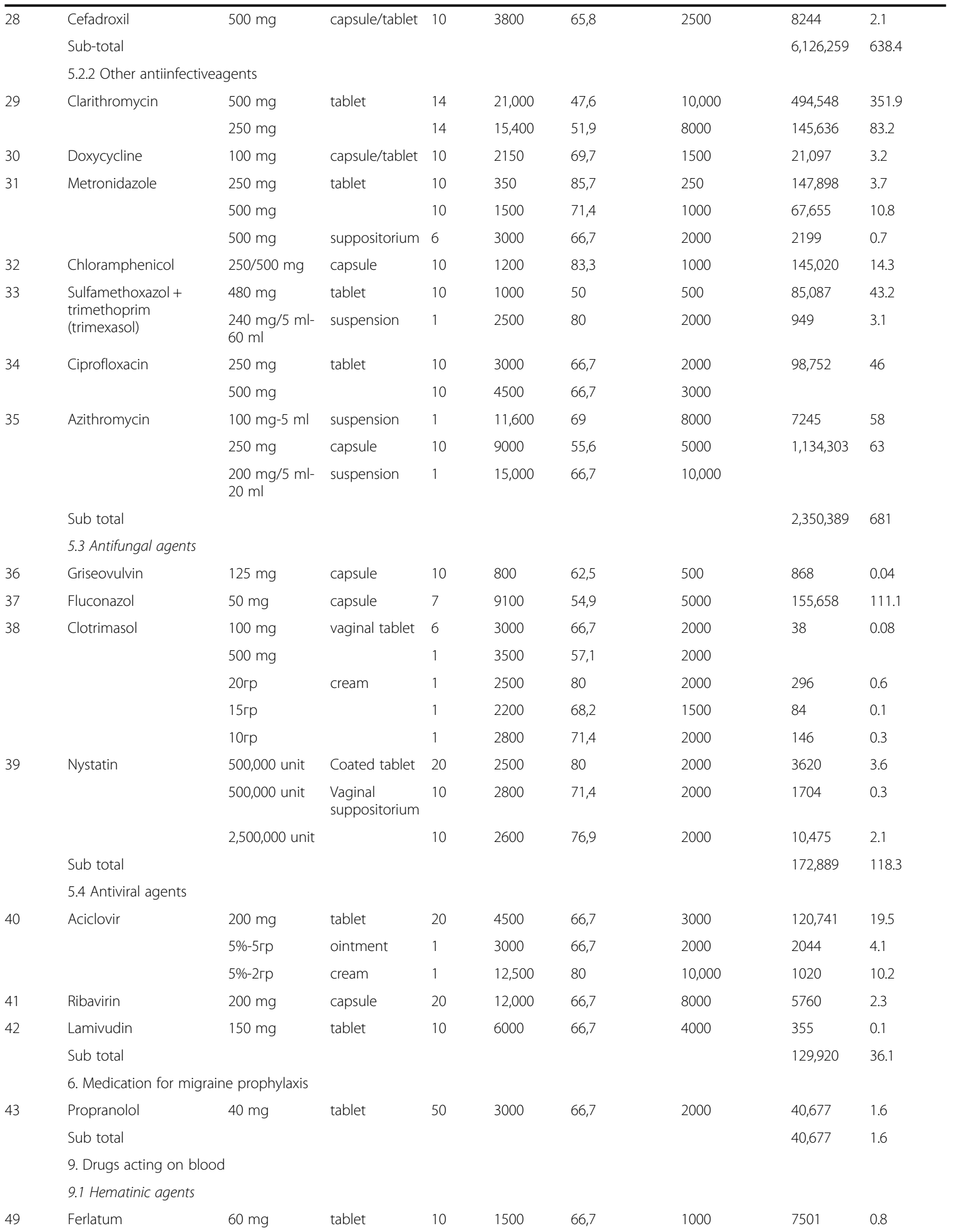


Table 1 Drug categories and reimbursement data for essential drugs for the year 2014 (Continued)

\begin{tabular}{|c|c|c|c|c|c|c|c|c|c|}
\hline 50 & Ferrovitum & $\begin{array}{l}162 \mathrm{mg}+ \\
0.75 \mathrm{mg}+ \\
7.50 \mathrm{mg}\end{array}$ & capsule & 30 & 5400 & 55,6 & 3000 & 121,772 & 12.2 \\
\hline \multirow[t]{4}{*}{51} & Folic acid & $5 \mathrm{mg}$ & tablet & 100 & 4000 & 50 & 2000 & 31,828 & 0.6 \\
\hline & Sub total & & & & & & & 161,101 & 13.6 \\
\hline & 10. Cardiovascular agent & & & & & & & & \\
\hline & 10.1 Drugs for Angina pe & ctoris, schen & heart diseases & & & & & & \\
\hline \multirow[t]{2}{*}{52} & Atenololum & $50 \mathrm{mg}$ & tablet & 30 & 3000 & 66,7 & 2000 & 330,066 & 21.9 \\
\hline & & 100 mg & tablet & 10 & 2000 & 50 & 1000 & 31,812 & 3.2 \\
\hline 53 & Verapamilum & $40 \mathrm{mg}$ & tablet & 50 & 3500 & 57,1 & 2000 & 16,038 & 0.6 \\
\hline 54 & Glycerilumtrinitratum & $6.4 \mathrm{Mu}$ & tablet & 25 & 4750 & 63,2 & 3000 & 5082 & 0.6 \\
\hline 55 & Isosorbidumdinitratum & $5 \mathrm{mg}$ & tablet & 20 & 900 & 55,6 & 500 & 80,812 & 2 \\
\hline 56 & Nifedipinum & $10 \mathrm{mg}$ & tablet & 50 & 2500 & 80 & 2000 & 809,139 & 32.3 \\
\hline \multirow[t]{3}{*}{57} & Inozinum & 200 mg & tablet & 50 & 2200 & 68,2 & 1500 & $1,250,837$ & 37.4 \\
\hline & Sub total & & & & & & & 253,786 & 98 \\
\hline & 10.2 Drugs for arrhythmia & & & & & & & & \\
\hline \multirow[t]{2}{*}{58} & Amiodarone & 200 mg & tablet & 30 & 7500 & 66,7 & 5000 & 50,865 & 8.5 \\
\hline & 10.3 Antihypertensives & & & & & & & & \\
\hline \multirow[t]{2}{*}{59} & Hydrochlorthiazidum & $25 \mathrm{mg}$ & tablet & 30 & 3000 & 66,7 & 2000 & 7869 & 0.5 \\
\hline & & & & 10 & 1200 & 83,3 & 1000 & 6557 & 0.6 \\
\hline 60 & Methyldopa & $250 \mathrm{mg}$ & tablet & 50 & 12,000 & 66,7 & 8000 & 60,237 & 9.6 \\
\hline \multirow[t]{2}{*}{61} & Amlodipin & $5 \mathrm{mg}$ & tablet & 30 & 16,200 & 61,7 & 10,000 & $1,578,754$ & 525.8 \\
\hline & & $10 \mathrm{mg}$ & tablet & 30 & 30,000 & 50 & 15,000 & $6,135,264$ & 3059.5 \\
\hline \multirow[t]{4}{*}{62} & Enalapril & $2.5 \mathrm{mg}$ & tablet & 20 & 3000 & 66,7 & 2000 & 25,525 & 2.5 \\
\hline & & $5 \mathrm{mg}$ & tablet & 30 & 3900 & 76,9 & 3000 & 310 & 0.1 \\
\hline & & 10 mg & tablet & 30 & 5400 & 74,1 & 4000 & 1260 & 1.7 \\
\hline & & 20 mg & tablet & 30 & 8100 & 61,7 & 5000 & 1580 & 2.4 \\
\hline \multirow[t]{3}{*}{63} & Lozartan & $25 \mathrm{mg}$ & tablet & 28 & 10,500 & 76,2 & 8000 & 190,397 & 54.4 \\
\hline & & $50 \mathrm{mg}$ & tablet & 28 & 14,000 & 71,4 & 10,000 & $1,105,003$ & 393.7 \\
\hline & & 100 mg & tablet & 28 & 28,600 & 52,4 & 15,000 & & 0 \\
\hline \multirow[t]{5}{*}{64} & Lizinopril & $5 \mathrm{mg}$ & tablet & 14 & 5500 & 54,5 & 3000 & & 0 \\
\hline & & $10 \mathrm{mg}$ & tablet & 14 & 7000 & 57,1 & 4000 & & 0 \\
\hline & & $20 \mathrm{mg}$ & tablet & 14 & 8500 & 58,8 & 5000 & & 0 \\
\hline & Subtotal & & & & & & & $9,112,756$ & 405.9 \\
\hline & 10.4 Heart failure & & & & & & & & \\
\hline \multirow[t]{3}{*}{65} & Digoxin & $250 \mathrm{mkg}$ & tablet & 30 & 3000 & 66,7 & 2000 & 6269 & 0.4 \\
\hline & Sub total & & & & & & & 6269 & 0.4 \\
\hline & 10.5 Lipid lowering drugs & & & & & & & & \\
\hline \multirow[t]{5}{*}{67} & Simvastatin & $10 \mathrm{mg}$ & tablet & 30 & 13,200 & 60,6 & 8000 & 65,260 & 17.4 \\
\hline & & $20 \mathrm{mg}$ & tablet & 30 & 22,000 & 45,5 & 10,000 & 322,778 & 107.6 \\
\hline & & $40 \mathrm{mg}$ & tablet & 30 & 36,000 & 50 & 18,000 & 587,264 & 352.3 \\
\hline & Sub total & & & & & & & 975,302 & 477.3 \\
\hline & 14. Diuretics & & & & & & & & \\
\hline 77 & Spirinolactone & $25 \mathrm{mg}$ & tablet & 20 & 4200 & 71,4 & 3000 & 344,164 & 51.5 \\
\hline \multirow[t]{2}{*}{78} & Furosemide & $40 \mathrm{mg}$ & tablet & 30 & 800 & 62,5 & 500 & 23,333 & 38,410 \\
\hline & Sub total & & & & & & & 346,497 & 38461.5 \\
\hline
\end{tabular}


Table 1 Drug categories and reimbursement data for essential drugs for the year 2014 (Continued)

\begin{tabular}{|c|c|c|c|c|c|c|c|c|c|}
\hline \multirow[b]{2}{*}{125} & \multicolumn{9}{|l|}{ 21. Vitamins and minerals } \\
\hline & Ascorbucacidm & $50 \mathrm{mg}$ & tablet & 10 & 200 & 50 & 100 & & 0 \\
\hline \multirow[t]{3}{*}{126} & Vitamin B complex & $\begin{array}{l}100 \mathrm{mg}+ \\
200 \mathrm{mg}+ \\
300 \mathrm{mkg}\end{array}$ & dragee & 60 & 3200 & 62,5 & 2000 & & 0 \\
\hline & & $\begin{array}{l}100 \mathrm{mg}+ \\
200 \mathrm{mg}+ \\
300 \mathrm{mkg}\end{array}$ & coated tablet & 10 & 1700 & 58,8 & 1000 & & 0 \\
\hline & & $\begin{array}{l}250 \mathrm{mg}+ \\
250 \mathrm{mg}+ \\
1000 \mathrm{mkg}\end{array}$ & tablet & 10 & 3600 & 76,9 & 2000 & 88,708 & 17.6 \\
\hline 127 & Calcium gluconate & $500 \mathrm{mg}$ & tablet & 10 & 250 & 40 & 100 & 59,066 & 0.6 \\
\hline 128 & $\begin{array}{l}\text { Calcium } \\
\text { glycerphosphate }\end{array}$ & $500 \mathrm{mg}$ & tablet & 10 & 1200 & 83,3 & 1000 & 18,354 & 0.2 \\
\hline \multirow[t]{3}{*}{129} & Polivitamine & 50 mg & dragee & 50 & 300 & 33,3 & 100 & 78,739 & 0.2 \\
\hline & & 150 mg & syrup & 1 & 8000 & 50 & 4000 & 66,666 & 264.4 \\
\hline & & $500 \mathrm{mg}$ & Coatedtablet & 10 & 1200 & 83,3 & 1000 & 18,794 & 1.9 \\
\hline 130 & Nicotinamide & $50 \mathrm{mg}$ & tablet & 10 & 800 & 62,5 & 500 & 15,518 & 0.8 \\
\hline 131 & Pyridoxine & $20 \mathrm{mg}$ & tablet & 10 & 400 & 75 & 300 & 740 & 0.02 \\
\hline \multirow[t]{2}{*}{132} & Retinolumpalmitatum & 20 mg & dragee & 10 & 1100 & 45,5 & 500 & 18,678 & 0.9 \\
\hline & & $12,000 \mathrm{IU}$ & capsule & 10 & 900 & 55,6 & 500 & 10,868 & 0.5 \\
\hline 133 & Ergocalciferol & $\begin{array}{l}15,000 \mathrm{IU} \\
1 \mathrm{ml}\end{array}$ & solution & 1 & 4500 & 66,7 & 3000 & 553 & 1.7 \\
\hline \multirow[t]{2}{*}{134} & Thiamine & $50 \mathrm{mg}$ & tablet & & 700 & 71,4 & 500 & 1150 & 0.1 \\
\hline & Sub total & & & & & & & 88,708 & 17.6 \\
\hline
\end{tabular}

with limited health funding. However, $\mathrm{HI}$ involvement in the decision making process, the use of evidence-based data, including post marketing analysis, cost-effectiveness analysis are lacking. The different aspects and number of various institutions involved leads to complexity in the current system which can have a negative impact on health care delivery, including increased OOP payment for drugs. Obviously, this is a major point where the vast array of government departments and offices involved must make the system fragmented and avoid much duplication.

The funding source of pharmaceuticals in Mongolia was analysed and the non-government sources including the donor organizations and patient OOP, played a minimal role for total pharmaceutical expenditure (TPE) (4.8\%) whereas government sourced fund (tax) was the highest (80.4\%) [19]. No data are available on private health funds in Mongolia. Previous findings reported that OOP payments for health services have increased from $14.5 \%$ of the THE in 1995 to $41.4 \%$ in 2010. However, data in regards to OOP payments for pharmaceuticals were not available $[19,20]$. The WHO reviewed the total expenditure on pharmaceuticals in different countries and compared by GDP. The median expenditure for pharmaceuticals in European region was 13\% and Asian countries spent approximately $35 \%$ of total health expenditure on pharmaceuticals. However, the data represent both public and pharmaceutical expenditure [20]. The comparison of proportion of pharmaceutical expenditure in different regions indicated that Mongolia had the lowest public pharmaceutical expenditure (11.6\%) [20].

It is widely accepted that modern health technology assessment methods should be used in such processes [21]. Successfully implemented health technology assessment programs including the evaluation of efficacy, comparative cost-effectiveness of medical interventions and published clinical guidelines as can be seen in Australia [22], Canada [23] and UK [23]. Even though it is difficult to create a system that satisfies all stakeholders, the Mongolian pharmaceutical sector needs to expand its assessment processes and report more relevant data in order to allow the analysis of the pharmaceutical sector and develop coordinated systems for decision making in drug reimbursement.

\section{Limitations}

The lack of evidence-based data on private health fund and OOP payment for pharmaceuticals as well as the price components for locally produced or imported medicines, including lack of cost-effectiveness data limit 
study results to generalize for the pharmaceutical sector in Mongolia.

\section{Conclusions}

Drug pricing and reimbursement of essential medicines is an important task shared by many different authorities, including Ministry of Health and Sport and Ministry of Finance in Mongolia. Periodical reports of the drug registration process, average registration duration and decisions for drug registration are available. However, there is a lack of publicly available reports for the reimbursement decision making process, whereas only information related to drugs that can be reimbursed is made publicly available once consensus has been reached. Price negotiation, budget impact and costcontainment are essential elements for a drug reimbursement process. To allocate resource efficiently in Mongolia is an important and challenging task. Currently the overall system is too complex and there is a lack of accessible data to permit a detailed analysis of the pharmaceutical sector, which is necessary to drive decisions.

\section{Abbreviations}

CIF: Cost, insurance and freight; DOH: Department of Health; DOPS: Department of Physical Culture and Sport; DRF: Drug Revolving Fund; GASI: General Agency for Specialised Inspection; GDP: Gross Domestic Product; GMP: Good manufacturing practice; HI: Health Insurance; HIF: Health Insurance Fund; MNT: Mongolian National Tugrug; MOES: Ministry of Education and Science; MOF: Ministry of Finance, Mongolia; MOH: Ministry of Health of Mongolia; MOHDSW: Ministry of Human Development and Social Welfare; NMPM: National Drug Policy of Mongolia; OOP: Out of pocket; OTC: Overthe-counter; SHIO: Social Health Insurance Office and the; SIGO: Social Insurance General Office; SINC: Social Insurance National Council; THE: Total health expenditure; TPE: Total pharmaceutical expenditure; USD: United States dollar; VAT: Value-Added-Tax; WHO: World Health Organization

\section{Acknowledgement}

We would like to acknowledge Dr.Naranchimeg and Dr.Batjargal for providing some useful information. Also, we thank the Division of Pharmaceutics and Medical Devices, Mongolian Ministry of Health and Sport, Ministry of Finance and Health Insurance of Mongolia for their feedback.

\section{Funding}

None.

\section{Availability of data and material}

Please contact author for data requests.

\section{Authors' contributions}

Gereltuya Dorj (GD) - Substantial contributions to conception and design, acquisition of data, or analysis and interpretation of data. Drafting the article and revising it critically for important intellectual content. BS- Drafting the article and revising it critically for important intellectual content. Substantial contributions to conception and design, acquisition of data, or analysis and interpretation of data. ST -Statistical analysis of the study results and review. Drafting the article and revising it critically for important intellectual content. Gantuya Dorj (GD)- Drafting the article and revising it critically for important intellectual content. Substantial contributions to conception and design, acquisition of data, or analysis and interpretation of data. BG - Drafting the article and revising it critically for important intellectual content. Substantial contributions to conception and design, acquisition of data, or analysis and interpretation of data. All authors read and approved the final manuscript.

\section{Competing interests}

The authors declare that they have no competing interests.
Consent for publication

Not applicable.

Ethics approval and consent to participate

Not applicable.

\section{Author details}

'Department of Clinical Pharmacy and Pharmacy Administration, School of Pharmacy and Biomedicine, Mongolian National University of Medical Sciences, Ulan Bator, Mongolia. ${ }^{2}$ School of Pharmacy, Faculty of Health Sciences, Curtin University of Technology, WA, Perth, Australia. ${ }^{3}$ School of Pharmacy and Biomedicine, Mongolian National University of Medical Sciences, Ulan Bator, Mongolia. ${ }^{4}$ Department of Epidemiology and Biostatistics, School of Public Health, Mongolian National University of Medical Sciences, Ulan Bator, Mongolia. ${ }^{5}$ ISPOR Chapter Mongolia, Bayanzurkh district, 76-26, 13374 Ulaanbaatar, Mongolia.

Received: 8 December 2016 Accepted: 4 February 2017

Published online: 27 February 2017

\section{References}

1. Ariuntuya S, Narantuya Kh, Davaajargal S, Enkhjargal TS, Unurtsetseg T. Health Indicators of Mongolia Ulaanbaatar Mongolia Health Department of Mongolia 2014 [cited 10/10/2015]. Available from: http://www.chd.mohs. mn/images/pdf/sma/uzuulelt/eruul_mendiin_uzuulelt_new_size_8_font_ 12_curuv.pdf.

2. Tsolmongerel Tsivaajav, Evlegsuren Ser-Od, Bulganchimeg Baasai, Ganbat Byambaa, Shagdarsuren. O. Health Systems in Transition Mongolia Health System Review Issue 2, 2013

3. Ministry of Health Mongolia. Annual report of Ministry of Health Mongolia. 2014.

4. Dorj G, Hendrie D, Parsons R, Sunderland B. An evaluation of prescribing practices for community-acquired pneumonia (CAP) in Mongolia. BMC Health Serv Res. 2013;13(1):379. Available from: http://www.biomedcentral. com/1472-6963/13/379.

5. Chimedtseren M. Survey of medicine prices, availability, affordability and price components in Mongolia. 2012.

6. Nakajima R, Takano T, Urnaa V, Khaliun N, Nakamura K. Antimicrobial use in a country with insufficient enforcement of pharmaceutical regulations: a survey of consumption and retail sales in Ulaanbaatar, Mongolia. Southern Med. 2010;3(1):19-23. Available.

7. Dorj G, Sunderland B, Hendrie D, Parsons R. Parenteral medication prescriptions, dispensing and administration habits in Mongolia. PLoS One. 2014;9(12):e115384. Available.

8. Oyungerel. Hospital services costing survey at aimag and district health facilities. Ulaanbaatar; 2011.

9. Ministry of Health Mongolia. Essential Drug List of Mongolia, 5th revision. Ulaanbaatar; 2009.

10. World Bank. How we Classify Countries. World Bank; 2013 [cited 21/05/2013]. Available from: http://data.worldbank.org/about/country-classifications.

11. Mongolia MoHaSo. Pharmaceutical indicators of Mongolia. 2014.

12. Mongolia MoHaSo. Reimbursed medicines list of Mongolia. 2014.

13. Oortwijn W, Mathijssen J, Banta D. The role of health technology assessment on pharmaceutical reimbursement in selected middle-income countries. Health Policy. 2010;95(2):174-84. Available.

14. Harkness JA, Schoua-Glusberg A. Questionnaires in translation, 1998 DEU

15. Ministry of Health Mongolia. National Drug Policy of Mongolia. 2002.

16. Ansaripour A, Uyl-de Groot CA, Steenhoek A, Redekop WK. The Drug Reimbursement Decision-Making System in Iran. Value in Health Regional Issues. 2014:3:174-81. Available.

17. Group OB. The Report: Mongolia 2014. 2014

18. Soumerai $S B$, Ross-Degnan D, Fortess EE, Abelson J. A critical analysis of studies of state drug reimbursement policies: research in need of discipline. Milbank Q. 1993;71(2):217-652.

19. Dorj G. International Society for Pharmacoeconomics and Outcomes Research Public pharmaceutical expenditure of Mongolia 2015. Philadelphia, PA

20. Bennett S, Quick JD, Velasquez G. Public-private roles in the pharmaceutical sector: Implications for equitable access and racional drug use. In: Publicprivate roles in the pharmaceutical sector: Implications for equitable access and racional drug use: OMS; 1997.

21. Attaran A. How do patents and economic policies affect access to essential medicines in developing countries? Health Aff. 2004;23(3):155-66. Available. 
22. George B, Harris A, Mitchell A. Cost-effectiveness analysis and the consistency of decision making. Pharmacoeconomics. 2001;19(11):1103-9. Available.

23. Eichler HG, Kong SX, Gerth WC, Mavros P, Jönsson B. Use of CostEffectiveness Analysis in Health-Care Resource Allocation Decision-Making: How Are Cost-Effectiveness Thresholds Expected to Emerge? Value Health. 2004;7(5):518-28. Available.

Submit your next manuscript to BioMed Central and we will help you at every step:

- We accept pre-submission inquiries

- Our selector tool helps you to find the most relevant journal

- We provide round the clock customer support

- Convenient online submission

- Thorough peer review

- Inclusion in PubMed and all major indexing services

- Maximum visibility for your research

Submit your manuscript at www.biomedcentral.com/submit 